Copyright (@ 2009 Institute of Electrical and electronics Engineers, Inc.

All Rights reserved.

Personal use of this material, including one hard copy reproduction, is permitted.

Permission to reprint, republish and/or distribute this material in whole or in part for any other purposes must be obtained from the IEEE.

For information on obtaining permission, send an e-mail message to stds-igr@ieee.org.

By choosing to view this document, you agree to all provisions of the copyright laws protecting it.

Individual documents posted on this site may carry slightly different copyright restrictions.

For specific document information, check the copyright notice at the beginning of each document. 


\title{
A Case Study of Cross Cultural Communication Issues for Filipino Call Centre Staff and their Australian Customers
}

\author{
Proceedings Manuscripts
}

\author{
Alison Owens \\ Central Queensland University Sydney International Campus \\ owensa@syd.cqu.edu.au
}

\begin{abstract}
The off-shoring of telecommunications contimues to expand achieving near to $70 \%$ compound annual growth over the last five years in the global off-shoring of business telephone services. Despite this significant success, selling business services or products over the telephone across culture presents challenges to telemarketers over and above those challenges conventional to mono-cultural business environments. Communicating with strangers across culture is challenging, particularly when the interlocutors do not share the same first language. When this exchange is limited to telecommunication mode, such obstacles may become inflated, yet little research-based literature exists on the topic. This paper reports on a case study of Filipino call-centre staff working in a multinational CRM company contacting Australian customers. Operational and management staff were engaged in a series of interviews over a period of several months and conversational analysis of phone calls was conducted in order to identify the key sociocultural and sociolinguistic challenges for telemarketers with culturally remote customers. This paper explored the extent to which cultural difference affected staff performance and customer satisfaction. Findings suggest that there is functional cultural alignment between Filipino staff and Australian customers and that cross-cultural training and cross cultural immersion in the target community can assist call centre staff cross the boundaries of language and identity with greater success.
\end{abstract}

Keywords: cross-cultural communication, offshoring, call centres

\section{$\underline{\text { Introduction }}$}

Offshoring business activity has been a growing trend since the 1980 s when the manufacturing industry moved blue-collar production to offshore countries such as India and China, attracted by lower wages and operating costs. Specific service industries have followed, notably call centres, as technological development has allowed for business processes to be performed remotely from the customer and from colleagues. Currently, offshoring extends across industries inclusive of software engineering, back-office processes, financial services and more recently, research and development. There has been significant anxiety in relation to this emergence of an increasingly de-regulated, single, global labor market, most critically, over concerns that domestic jobs are being lost to overseas talent, that overseas workers are at risk of exploitation in relation to wages and conditions and that the quality of service to the customer (where the work is 'service' based) is inferior. This paper explores these concerns with a particular focus on the quality of crosscultural customer service through a case study of telephone communications between Filipino call centre staff employed by a multinational CRM (Customer Relationship Management) company to service Australian customers.

\section{Key issues in offshoring}

Much of the literature and reporting around offshoring of telecommunications, both the economic and social effects, revolves around the US or the UK with little if any investigation of how Australian customers are responding to telephone calls from offshore staff working for Australian or multinational companies. As the US is currently responsible for almost $70 \%$ of call centre offshoring [1] this is not surprising.

Claims that offshoring is contributing to the impoverishment of the US worker are disputed on the combined grounds that $69 \%$ of US workers who lost nonmanufacturing based work to overseas labor found reemployment in the period from 1979-1999; $70 \%$ of US service-based work is not offshorable and the US economy will need 15,6 million more workers by 2015 to 
maintain its worker-population ratio and its living standards as its population ages $[1,2,3]$. Cost savings from offshoring are, of course, reflected in the repatriated earnings of the organisation and thereby improve returns for domestic shareholders [2]. An important further benefit of offshoring for organisations and their customers is the option of a 24 hour productivity cycle, if offshored offices are in spread time zones improving turn around time on business processes and services. Despite the varied concerns and risks raised over the practice of offshoring business processes, trends indicate continuing growth. With careful management of offshoring activities, benefits are evident not only for domestic economies but all participating communities [2].

Although criticisms of offshoring have included claims of exploitation of workers in overseas communities the majority of offshore operators pay wages equivalent to but usually higher than those offered by local competitors $[2,4]$. However, there are benefits to call centre offshoring that are not exclusively economic. In the first place, call centre work has traditionally been considered low-value employment by the majority of workers in developed countries and has experienced high attrition rates, absenteeism and recruitment problems. American, Canadian, British and Australian workers tend to see the work as repetitive, routine and pressurized $[4,5]$ and so a stop-gap or stepping stone rather than a career. With unemployment measuring between $4 \%$ and $5 \%$ over the last few years [6], Australian call centre employers are finding it difficult to attract adequate domestic talent. In contrast, workers in developing countries, such as India and the Philippines, are able to attract comparatively high wages in call centre work for foreign companies. In the Philippines, a call centre worker can attract an average salary of (US)\$327 per month before commission compared to the average monthly wage of (US)\$261 [7]. In the Philippines, the profession attracts highly-skilled university graduates who see career-path potential in call centre work [8].

The Philippines is the new success story in offshoring call centres with 20 percent of the total world market share or 100,000 seats in 128 centres [9] and the Philippine Business Process Association is seeking to double this by 2010 [10]. The Philippines is an attractive offshore site for call centre work not only because it offers cheap, educated talent, but the graduate population also have well-developed English language skills as a consequence of US colonization and affiliation. From the perspective of US based companies, there is an added advantage in that Filipino English speakers have an American-influenced accent. Dell recently ranked its Philippines call centre first in terms of quality of performance from its total of 25 offshore call centre teams and is currently strengthening its presence there as a consequence [9].
The most common reason for negative customer assessment of overseas callers is difficulty in understanding accents' [11] and this can and has lead to customer defection on the basis of call centre interaction alone [12]. A recent report by CFI Group on customer satisfaction with call centres indicated that service representatives located outside the US are rated significantly lower on communication skills [12] by US customers and accent can be reasonably supposed to impact on this perception.

Accent is clearly an aspect of communication. Indeed, in the non-visual context of a telephone call, it is a key identifier of an offshore caller for an English speaking customer. Accent is also a sensitive topic as accented speech can generate both negative and positive associations in the mind of the listener $[13,14,15,16$, 17]. An argument for the 'correctness' of any particular accent in English is increasingly ideologically and technically problematic due to a complex of factors including the range of 'standards' in first language English pronunciation, the proliferation of 'new' English varieties particularly in ex-colonies and the steadily increasing numbers of non-native English speakers using English in the globalised context of business and communications. More people now speak English as a second language than a first language and the language itself and patterns of usage are changing as a result [18].

In this study, two key aspects of accent are considered in order to clarify its role in communicative success in the offshore call centre context: firstly, proximity/distance between the first languages of any speaker and listener; and secondly, interlocutors' familiarity with each other's specific first language accent [19]. Derwing, Thompson and Munro point out that "... intelligibility is determined not only by the speaker, but by the listener as well," [19]. Offshoring organisations are clearly aware of this seeking 'cultural alignment' in their selection of offshore service staff for specific domestic culture customer groups. This may involve 'blended delivery' or 'right shoring' where offshore, near shore and onshore teams are matched to different customer groups on the basis of perceived cultural alignment

'Cultural alignment' is an approach to offshoring that is proving more palatable to customers than more radical approaches adopted by some call centre organisations. Current trends in call centre training in offshoring organisations include 'accent training' or 'neutralisation' for service staff. Some organisations go so far as to encourage their staff to create westernized pseudonyms and conceal their location from the customer [4] in order to minimize customer issues.

A recent Australian television documentary Diverted to Delhi (2003) aired footage of Indian call centre workers being trained to speak like Australians, create Australian names and visit Australia to learn more about the culture and accent. Public reaction was negative and 
the contract was returned to Australia. The documentary foregrounded the concerns of industry union representatives about potential loss of Australian jobs to overseas workers and so it is difficult to identify whether negative public reaction was to potential job loss rather than such training strategies. Regardless of important ethical questions about 'neutralising' a person's accent, any attempt to mislead customers is a high risk endeavour for customer service organisations that value their integrity and credibility. Such efforts may have the potential to alienate customers more critically than a nonstandard accent.

The Filipino-Americanised accent appears to create a greater sense of cultural affinity for US customers than a non-American influenced accent, as Indian or Chinese English speakers may use. However, how does this work for Australian telephone customers? Again, as offshoring remains a US dominated trend at this point, many US based multinational organisations publish claims that are true only for a domestic American audience, as in: 'With minimal accent and an affinity to western culture our friendly staff are well suited to meet your needs' [20]. Such language may need to be revisited to enhance relevance to non-US clients receiving calls from Filipino staff.

Australians have a complex attitude to American culture often explained as a fear of becoming the $51^{\text {st }}$ state of the USA. A recent survey [21] reports that $52 \%$ of Australian respondents were 'very unhappy' with the influence of the American language on the way Australians speak. There is a possibility that the American influence evident in Filipino English may not translate into a perceived 'cultural affinity' as it might for US customers. Nevertheless, the high level of exposure of Australians to American culture and language would suggest that intelligibility might be enhanced for Australian listeners, if a second language accent is aligned to standard North American variety.

Recent strategies for enhancing cultural alignment in offshored call centre processes include cultural immersion training for offshore call centre staff. This study sought to identify the intercultural and linguistic issues in business telephone communications between Filipino staff immersed in the Sydney office of a US-based CRM company and their Australian customers.

\section{Research method}

This paper reports on a case study of the Australian branch of a US based multinational company specializing in CRM business solutions. In order to achieve a multiperspectival understanding of the communication patterns and issues for Filipino telemarketers and their Australian customers, research method included:
- listening to randomly sampled outbound sales calls (approximately 13 hours total @ 34 calls, approximately $60 \%$ Filipino callers, $40 \%$ domestic callers)

- focus group interviews with two groups of five Filipino call centre staff in the Sydney office

- one to one interview with executive management in the Sydney office.

The objective of the research was to explore cross cultural issues in communicating over the phone in business contexts. It was useful to seek the opinions and experiences of the telemarketing staff as well as listen to the actual calls in order to identify and assess where communication was successful, partially successful or unsuccessful as a consequence of intercultural difference. Outbound calls involving on-selling of new products to existing customers of business clients were selected as outbound calls are traditionally more challenging than inbound calls and this reflected the typical work of the Filipino trainees in Sydney.

Anonymity of caller and customer identity has been preserved and names changed where names are required to demonstrate a linguistic point. The objectives and opinions of key management staff were also sought in order to develop a rich understanding of the case population and their activity.

\section{Case synopsis: the CRM Company}

This US-based CRM solutions company has been operating since 1983. Offshore activity began in 1996 and currently the organisation has 20,000 sales and service representatives worldwide in over forty operations centers throughout North America, Europe, Latin America, Australia, India and the Philippines. The company has a strong presence in Manila, the Philippines, with a captive call centre of over 8000 seats (company-operated rather than outsourced). The staff at this call centre provide telephone based customer services to Americans (in the 'graveyard shift') and Australians amongst other smaller customer population groups. The Manila call centre venture has been very successful and the Australian office has recently introduced an immersion training strategy that allows some of their Manila-based call centre staff to spend two or three months in Sydney Australia, working in the Sydney office. This strategy was aimed at enhancing the operators' understanding of Australian culture as well as working as an incentive/reward for staff who were performing well with overseas customers. The staff are paid their usual wages, plus accommodation and daily living allowance and are flown economy return at the expense of the company. The staff engaged in focus group research and in telephone call analysis had been located at the Sydney office for between one and two months when they were interviewed. 


\section{$\underline{\text { Results }}$}

\section{Focus group interviews}

The focus group questions were:

1. How are Australian telephone customers different to other customers?

2. What are the most difficult aspects of speaking with Australian telephone customers?

3. What have you done to adjust your approach to Australian customers?

4. How does immersion in the customer culture help in your work?

5. What advice would you give to the next group of Filipino telemarketers engaged in Australian immersion training?

In answer to question 1, all of the ten interviewees engaged in comparing their Australian customers with their American customers. This is because they had a history of working with American customers and they used this comparative strategy to clarify their experiences with Australians. In comparing the two different customer groups, the most frequently referred to factor of difference was customer 'politeness'. The Filipino staff found that Australian customers were 'very much polite', 'really polite', and 'more accommodating'. This was usually explained in terms of preparedness to listen:

'...US customers want to be straight to the point,.. no beating around the bush. Time is very important for them, it's like, ... okay, you have two minutes, don't waste it, say what you want... but for Australians, it's very different, they will listen to you for a long time and expect you to speak slow and put some sugar coating on the words..'

Whilst the staff reported many American customers hang up the phone, if they don't want to talk, they said Australian customers don't tend to do that and callanalysis confirmed this with no customers hanging up on Filipino or non-Filipino callers in the 34 sample tapes. Comments such as, 'Aussies are more laid back', 'they like to go more slowly', they 'like a conversation so you need more information' were common amongst the respondents.

Of course, this was not always a gain in efficiency and respondents expressed both pleasure and frustration at the amount of time invested in conversational calls which did not produce a sale:

'Sometimes, after you list all the features, all the conditions, and all the benefits, you know, yatta-yatta, and then after all that, they say, okay, that's nice, but I am sorry I am not interested.. (laughter)."

Some customers were so laid back that they took many minutes to locate required documents in handbags, offices, on other calls, with one woman confessing that she had to move her car whilst the terms and conditions were being read.

In answer to question 2 staff commented on the differences between accents of American and Australian customers. They found that it took some time to understand Australian pronunciation, particularly ' $A$ ' and ' $\mathrm{H}$ ' and ' $\mathrm{Z}$ '. In listening to calls, it was clear that the Australian pronunciation of the diphthong vowel 'ei' as in 'face' pronounced as 'ei' by Americans (lips wide but fairly close together) but pronounced /æI/ (lips more rounded and mouth more open) by Australians. The Filipino staff frequently confused the Australian efforts to spell using the letter ' $A$ ' with the letter ' $E$ '.

Customer: That's A-N-B

Staff: Okay E-N..

Customer: No, $\mathrm{A}$, as in apple.

Staff: Oh $\underline{A}-\mathrm{N}-\mathrm{B}$

The alphabet is a resource frequently used for spelling purposes over the phone. The lack of visual cues in telephone conversations has been frequently noted, referred to as a 'cueless' situation by Rutter [22]. To clarify information shared over the telephone, it is frequently necessary to spell terms and culturally distinct pronunciations of the letters of the alphabet can interfere significantly with these attempts at clarification particularly as acronyms proliferate in business and technology discourse. Most Australians say 'haitch' rather than 'aitch' and 'zed' rather than 'zee'. For Filipino English speakers, this takes some getting used to. It creates scenarios such as:

Caller:... and what is your employer's name?

Customer: HPS

Caller: Sorry?

Customer: H-P-S

Caller: Could you please spell that out for me?

Customer: (silence)...uh,.. Haitch for happy....

In addition to differences in pronunciation of the letters of the alphabet, certain contrasts in American/Australian vocabulary, such as 'lift' for 'elevator' and 'tap' for 'fawcett' and colloquial distinctions like 'no worries' for 'no problem', 'mate' for 'buddy' and 'rightio' for 'all right' interfered little with understanding.

Interestingly, in answer to this question, most of the staff referred to their own difficulty understanding Australians but two commented on the difficulty some customers had understanding their American influenced accents also. As it is the caller who needs to document accurately the information exchanged, it seems natural to focus on caller problems rather than customer. Indeed, company management reported no complaints in relation 
Caller: What is your occupation?

Customer: Pharmacy technician

Caller: (silence 26 seconds)... what exactly is the nature of your work?

Customer: I'm a pharmacy technician,.. I work with hospitals and medicines as a technician dispensing and,... I mean,... there's not much, ....you simply supply hospitals and that with their medicines, a pharmacy technician...

Caller: Okay.

Whilst culturally specific knowledge and language affinity between Australian callers and Australian customers allowed for full comprehension of auxiliary information, there is no evidence that this positively affected the outcome of the call. In fact, it tended to result in more discussion of information not relevant to the purpose of the call, including ill health, work problems, family issues and shared histories or interests between caller and customer.

In all the calls (34) only one customer asked where the telephonist was calling from and this was in the context of small talk while she searched her mobile phone for a reference number:

Customer: Where are you calling from today?

Caller: We are calling from XXX Australia on behalf of (client)

Customer: What state are you in?

Caller: Actually XXX is in Sydney Australia

Customer: oh, okay

Deciding on forms of address for customers and sticking to them was another issue of some difficulty. All of the callers initiated the call by establishing they were talking to the target customer referring to them as $\mathrm{Mr}$ or Miss, Ms + Surname. In several calls the caller asked if they could call the customer by first name and this was accepted in all instances. In one instance, the customer requested it:

Customer: Call me Ray, it's okay

Caller: Sorry?

Customer: Call me Ray, no worries you don't need to keep calling me by my surname.

Caller: So it is all right for me to call you by the first name?

Customer: No worries, go for it

Caller: So you're Mr Ray?

Customer: Yes R-A-Y

Confusing first name and last name and combining the honorific such as Ms with the first name of the customer as in Ms Debbie, was a common mistake made in almost all calls but no customers pointed this out. It was not uncommon for callers to revert to 'mam' or titled address even though they had established first name address.

Several customers attempted humorous comments but, as is frequently noted in cross cultural communication, studies humour does not translate easily across cultures and the staff were largely oblivious.

The following instances reflect the Australian love of ironic observation:

Caller: And where were you born?

Customer: Where was I born!? Well, hopefully it was Manly,

Caller: So the place where you were born..?

Customer: Manly!

Caller: No worries Mam. Thanks Miss Grange.

Customer: Hello?

Caller: Hello Mr Johns, my name is Celia and I am calling you from World Bank. How are you today?

Customer: I'm a bit thirsty thanks.

Caller: Yes, Mr Johns, World Bank...

The customers on the other hand were sometimes amused by the cultural disparities in the conversation. One instance of this reflects the different standards of living between Australia and the Philippines and occurred when the caller attempted to assist the customer calculate their monthly expenses:

Customer: Expenses? Well, ...husband pays mortgage, husband pays health insurance,... um..

What do you want monthly?

Caller: Approximately,... yeah,... like around 200 a month?

Customer: Sorry?

Caller: 200?

Customer:...A month! (Laughs) ... I think it would be a bit more than that,... that's only about 25 dollars a week on food!..... I think about 1500 .

Again, these were benign limitations on communications and did not prohibit a successful transactional outcome.

Filipino-English linguistic idiosyncracies were evident in many calls, for example, in the use of 'already' for acts performed to expected schedule rather than acts performed exceptionally quickly :

Caller: Miss Wilson, I have already entered your personal details thank you...

The term, 'by the way' was use to introduce items in a listing/reporting back sequence as in: 
Caller: 'By the way, your name is .... And by the way, you live at...'

The phrase 'would be' rather than 'is', as in 'your name would be'..., was another habitual non-Australian linguistic habit used for reporting back. Whilst these were non standard usages of English terms for Australian English speakers, they did not impede understanding or attract comment from customers.

\section{Interview with management staff}

In an interview with the Australian Business Director for the Australian branch he explained that staff were positioned offshore in the Philippines and trained intensively in Australia in order to provide cheaper production opportunities for Australian business clients without compromising quality of customer service.

He commented that after a period of acclimatization which is a factor for all staff engaging with a specific client base, the Filipino staff achieved equivalent success rates with their customers to domestic Australian staff during their immersion training period. This was perceived as a significant improvement on their capacity which would be maintained on their return to Manila. They could then be confidently deployed to Australian accounts as demand required. In his assessment, the investment in such training by the company was more than returned by this productivity gain as well as the positive effect on staff retention.

When asked how Australian customers were responding to calls from Filipino staff he reported that the company had received no complaints about the staff on the basis of their ethnicity. In fact, company records indicate that the number of complaints received about calls from Filipino operators was equivalent to the complaints received about operators generally, that is, very low,

In support of this claim, a review of randomly sampled complaint calls was undertaken as part of call analysis. In seven calls filed as complaints in company data no complaints were about accent or ethnicity, instead focusing on omitted information, and most were generated by the company's own quality assurance staff listening to sample calls rather than customers.

\section{Discussion of results}

\section{$\underline{\text { Sociocultural issues }}$}

'Politeness' has been defined as 'appropriate communication' that avoids conflict and/or confrontation [22] but what is 'appropriate' in communication differs across cultures and what constitutes conflict or confrontational behaviour may also differ. Clearly,
Filipino call centre staff perceive hanging up the phone to be impolite. How does the US customer perceive hanging up the phone in this context?

Brown and Levinson have developed the most influential theory of politeness involving the maintenance or diminishment of 'face'. The notion of 'face' is comprised of positive face (preserving a person's selfimage) and negative face (avoiding imposing on a person's freedom) [23] and politeness, in the Brown and Levinson model, is achieved when each kind of face is preserved by and for interactants.

The seriousness of a face-threatening act is mediated by notions of social distance, relative power and absolute ranking [22]. So, whilst an American customer may agree that hanging up is normally impolite and threatens the negative face of the caller, where the caller is socially distant (unknown), has less power in the interaction (providing customer service) and imposing on the hearer's time (an unsolicited call), the 'face' of the caller may be of less significance to American customers than to Australian customers. The face threatening act of hanging up in this scenario is retribution-free so what might make Australians persevere where Americans will not?

The adage 'time is money' is a powerful American notion and so directness in communication is highly valued. 'Tell it like it is,' and 'get to the point' are popular expressions that reflect these American values. Whilst Australian culture is also focused on efficiency, Australians are fiercely egalitarian and go to great lengths to not give the impression that they are better than anyone else, hence referring to one another by first name is normally preferred regardless of prior acquaintance or social rank. This commitment entails significant attention to negative face maintenance. As hanging up the phone on anyone may indicate that the caller's time is not as important as the hearer's time, or that the caller does not have the right to impose on the hearer, it is probably less likely to happen in Australia at all as it constitutes a challenge to the negative face of callers and conflicts with the dominant commitment to egalitarianism.

America and Australia have similarly low tolerance for power-distance ( 40 and 36 respectively), that is, the unequal distribution of power in society as identified in Hofstede's influential study of cross-cultural difference [24]. In contrast, the Philippines has one of the highest tolerance levels for power-distance (94) of all countries in the survey second only to Malaysia (104) [24]. Filipino callers defer to the greater power of the customer with many face building strategies: compliments and commendations, as well as indirect methods of requesting information that maintain the negative face of the customer: as in such phrases as: 'would you care to listen..', 'may I read to you..' etc. The constant emphasis being on the customer's right to refuse further information and to control the call even though the customer is 
complying with the sale. Over time, the careful formalities and politeness strategies were reduced as the staff became more familiar with Australian culture. Many of the Filipino staff reported feeling 'very relaxed' with their Australian customers as the tendency was for customers to invite less linguistic formality rather than more.

Even though Americans are similarly committed to social equality, or an even distribution of power, as Australians, their 'doing' focus [25] or 'time is money' value may be more intense and so override their preference for egalitarianism in the context of marketing calls. Of course, the Australian customer's discomfort with hanging up does not necessarily translate into more sales, only longer calls. In the unsuccessful sales calls recorded in this study, Australian customers exhibited a strong tendency for providing indirect refusals based on a range of reasons, such as, 'too busy now', or 'already have something similar', rather than direct refusals or termination of call. Again, this demonstrates a desire to maintain the face of the caller. Whether this interpretation is true or not, the Filipino call centre staff welcomed the Australian customers' face-saving strategies even though they acknowledged these did not necessarily contribute to sales outcomes.

\section{$\underline{\text { Sociolinguistic issues }}$}

Filipino English has been influenced by the range of Austronesian languages in use across the 7000 islands, the most dominant being Tagalog. English has 42 phonemes whilst Tagalog has 21 phonemes. This creates varied effects on the Filipino pronunciation of phonemic items outside their native language. The consequence of such first language influence has created unique pronunciation patterns in Filipino English which are not always consistent with North American or Australian English pronunciation.

The Filipino-English pattern of pronunciation is often described as 'sing-song' although it is, as English is, a stress language rather than a tone language (where a change in pitch alters the meaning of a word as in Mandarin). Different variation in pitch and different patterns of word and sentence stress are evident between Filipino English and Australian English speakers. The Australian telephone customers tended to listen very intently to the Filipino callers with less side comment or overlapping speech than with non-Filipino callers. The Filipino staff frequently slowed down their utterance during calls in order to improve their intelligibility to their Australian customers and often repeated customer information to enhance clarity.

Nevertheless, first language interference was evident. For example, ' $F$ ' often becomes ' $P$ ' and ' $V$ ' often becomes ' $\mathrm{B}$ ' for Philippine speakers of English. $\mathrm{F}$ and $\mathrm{V}$ are labiodental fricatives that do not exist in Tagalog.
Filipino English speakers may have difficulty distinguishing these sounds and in the calls analysed the ' $\mathrm{P}$ ' and ' $\mathrm{B}$ ' sounds were frequently confused even when spelt rather than pronounced as part of a word.

The rhythm of sentences is an important aspect to language difference, even within the same language as it is spoken in different regions of the same country. In Tagalog stress is at the final syllable of each word and is very important as it can distinguish different meanings for the same word. In Australian English, stress is also important but can rest on the first syllable of a word, the middle syllable or the final syllable. We talk of metrical feet when discussing syllabic stress and there are two kinds of feet: left dominant or right dominant. English is left dominant (trochaic)with the stress usually on the first syllable. Tagalog is right dominant (iambic) and hence the languages are designed around different metrical theory. First language patterns of pronunciation, stress and intonation affect the ease listeners have in interpreting meaning [26].

There are more stressed moments in Filipino English than Australian and this tends to interfere with the way words are run together for example, 'You will also be able to take advantage' is enunciated by Australians as: 'You lalso beyabletu taykad vantage'. This creates twoway uncertainties and requires heightened effort in listening for both parties. The fast-paced delivery of utterance in the conventional phone sales call is not conducive to promoting intelligibility in these circumstances and the Filipino callers effectively slowed the tempo of their conversation to accommodate these challenges.

A strong feature of Australian speech is a raised intonation at the end of sentences confined to the ends of questions by most non-Australian English speakers. 'Upspeak' or 'Australian question intonation' has been a much observed feature of Australian speech [27]. Callers quickly became attuned to this practice and attempted to adopt the same pattern of intonation to enhance their comprehensibility. Living and working in the Australian community facilitated their ability and confidence in this respect.

Results from interviews and call analysis indicate a strong positive relationship between time spent in the English-speaking environment and ability to perceive and produce stress in a way that approximates that of the native speaker. Results also confirm reports of a strong relationship between using English in a variety of environments and situations and acquisition of English stress patterns [28].

\section{Conclusion}


In summary, despite much publicized concerns about the quality of call centre services to customers from offshore staff, Australian customers in this study were highly tolerant of cultural and linguistic differences evident in telephone conversations with Filipino-English speaking staff. Whilst there were sociocultural and sociolinguistic issues apparent in these exchanges, there was no evidence that these issues negatively impacted on the outcome of transaction or customer satisfaction.

Further conclusions evident from this research are:

- Australian customers are prepared to spend longer on the telephone with call centre staff than US customers but this does not necessarily translate into more sales

- Australian customers used colloquial terms of address and expressions but these rarely caused misunderstanding for Filipino staff

- Australian customers almost never enquired where the caller was from

- The Australian English accent causes difficulty in understanding particularly in the sounding of 'ei' and 'i:' for Filipino telephonists

- Spelling is an important tool for clarification of meaning oyer the phone but does not overcome problems in pronunciation of alphabetical elements

- The aviation alphabet is a useful resource to enhance communication between speakers of different accents but is inconsistently used by both staff and customers

- Australians tend to speak slower than Americans and also use a different intonation pattern which was effectively adopted by some callers

- Staff found Australian TV, particularly popular soaps like Neighbours were useful training materials for accent and rhythm practice

- No customers (total calls) commented on accent or difficulty in understanding on the telephone and complaints from Australians receiving calls from Filipino operators were no greater than complaints about domestic operators

- Filipino staff consciously attempted to slow their speaking rate for Australian customers

- Australians prefer to be addressed by name, usually first name, rather than by title

- Filipino naming systems differ from Australian and this causes some confusion for callers

- Culturally specific knowledge about place names, major institutions, acronyms and categories of employment were points of communication where some difficulty was experienced

- Humour does not translate effectively between Australian customers and Filipino callers
- Australian cultural immersion training for Filipino call centre staff enhanced staff awareness of culture specific as well as culture general difference; enhanced staff competence and confidence in dealing with Australian customers on the phone; enhanced staff loyalty to both the organization and the call centre industry

- Cultural immersion training is able to dramatically improve the performance of call centre staff over a period of approximately two months

- Cultural immersion training is perceived as an important career opportunity by Filipino staff and can be effectively deployed as a staff incentive by offshoring organisations

As the globalisation of business and communications in the medium of English continues to escalate, successful management of sociocultural and sociolinguistic differences between English speakers from different backgrounds is likely to become ever more important in all communities but particularly business communities engaged in offshoring. Results from this study indicate that whilst there are cross cultural communication issues for Australian customers and Filipino staff, these issues are benign and do not negatively effect customer satisfaction or transaction rates. Further research might explore the opinions of Australian customers receiving offshored calls as well as the comparative communicative success of other non-Australian call centre workers with Australian customers.

\section{References}

[1] Yawn, D., 'Taking Customer Service Offshore', Area Development Site and Facility Planning, 42:2, p.36, 2007

[2] Farrell, D \& Agarawal, V., 'Who Wins in Offshoring?' In D. Farell, (ed.) Offshoring: Understanding the Emerging Global Labor Market, Harvard Business School Press, Boston, 2006

[3] Palvia, S.C.J., 'Global marketing for Outsourcing IT and IT Enabled Services: Editorial preface', Journal of Global Information Technology Movement, 10:2, p.1, 2007

[4] Taylor P. \& Bain, P., 'Call Centre Offshoring to India: The Revenge of History?', Labour \& Industry, 14:3, 15-38, 2004

[5] Rubach, E., 'Customer Contact Centres: From Drones', Precision Marketing, p.23, July 27, 2007 
[6] Australian Bureau of Statistics, 'Labour Force, Australia, Jan 2008' viewed March 8, 2008 at: http://www.abs.gov.au/Ausstats/

[7] National Statistical Coordination Board, 'Economic and Financial Data of the Philippines', viewed March 7, 2008 at: http://www.nscb.gov.ph/sdds/nsdp.asp\#iii

[8] Datamonitor, The Global Pricing Guide to Offshore Outsourcing, Datamonitor, London, 2004

[9] Conti, M.K.C., 'English Skills no Longer Enough' Business World, August 9, 2007

[10] Smerd, J., 'The Philippines Vying to become the Next India', Workforce Management, 86:17, p.6, 2007

[11] Cards International, 'Is Outsourcing Really the Magic Bullet?' Cards International, July 11, 2007, viewed $3^{\text {rd }}$ March, 2008 [Proquest database]

[12] Michigan Banker, 'Banks Rated High in Customer Satisfaction with Call Centres', Michigan Banker, 19:7, p.31, 2007

[13] Collins, J., 'The Accent Ceiling', Education Links 51, University of Technology, Sydney, 1996

[14] Creese, G. and Kambere E.N., 'What ColourRias diour English?' The Canadian Review of Sociology and Anthropology. 40:5, 565-574, 2003, viewed September 12, 2007, [Thomson Gale Extended Academic Database]

[15] Findlay, M.A., Hoy, C. \& Stockdale, A., 'In what sense English? An exploration of English migrant identities and identification', Journal of Ethnic and Migration Studies, 30:1, 59-79, 2004, viewed May 23, 2007 [Proquest Academic Research Database]

[16] Munro M.J., Derwing, T.M. and Sato, K., 'Salient accents, covert attitudes: consciousness-raising for pre-service second language teachers'. Prospect 21:1, 67-79 NCELTR, Sydney, 2006

[17] Zuidema, L.A., 'Myth education: rationale and strategies for teaching against linguistic prejudice', Journal of Adolescent and Adult Literacy, 48:8, 2005, viewed June 17, 2007 [Thomson Gale Expanded Academic Database] 2007

[18] Crystal, D., How language works, Penguin: Cambridge,

[19] Derwing, T.M., Thomson, R.I., and Munro, M.J., 'English pronunciation and fluency development in Mandarin and Slavic speakers', System, 34:2, 183-193, 2006, viewed November 1, 2007 [Science Direct database]

[20] Call Offshore Co, 'Advert', viewed March 12, 2008 at http://www.calloffshore.com/?gclid=CLSywKyWgZICFR4dago d XTB-Q
[21] University of Sydney US Studies Centre, 'Survey of Australian Attitudes to the US', International Herald Tribune, December 10, 2007, viewed March 14, 2008 at: http://www.iht.com

[22] Rutter, D.R., 'The Role of Cuelessness in Social Interaction: An Examination of Teaching by Telephone', in D. Roger and P. Bull (eds), Conversation, Multilingual Matters, Clevedon, 294-312, 1989

[23] Bowe, H \& Martin, K., Communication Across Cultures: Mutual Understandings in a Global World, Cambridge University Press, New York, 2007

[24] Hofstede, G., Cultures and Organisations: Software of the mind, McGraw Hill, New York, 1999 1959

[25] Hall E.T., The Silent Language, Doubleday, New York,

[26] Harrington J, \& Cox, F., 'The Foot and Word Stress' Speech Science Resource Pages, Macquarie University, viewed March 14, 2008 at:

http://www.ling,mq.edu.au/speech/phonetics/phonology/syllable /syll_foot.html

[27] Collins, B \& Mees, I.M, Practical Phonetics and Phonology: A Resource Book for Students, Routledge, New York, 2003

[28] Negrin-Christiana, J., 'Do Non-Native Speakers of English Acquire English Stress Patterns?, 1997, viewed March $2^{\text {nd }}, 2008$ [ERIC database]

\section{About the Author}

Alison Owens has been teaching international students in Australian for twenty years, initially in ESL college contexts and then in Universities in Sydney including Central Queensland University Sydney International Campus where she has worked for the past twelve years as lecturer, Academic Director and now Senior Research Associate. Alison was awarded a Doctorate in Education from UTS in 2005 with the topic Intercultural Awareness and Sensitivity in an Australian University: a study of professional practice of University staff. She has completed numerous conference papers around issues of cultural diversity particularly in teaching and learning. Topics include stereotyping of international students; international student expectations around collaborative class work and teacher-student relationships, and student perceptions of non-native English accents. Alison received a Teaching and Learning Grant in 2006 to research second language reading comprehension of academic text. She has been instrumental in the development of a first year Course Principles of University Learning which seeks to transition new students into the critical model of western academic practice. She has played a leadership role in developing a new Program for introduction in 2007 Graduate 
Certificate Teaching English as a Foreign Language.

Currently, Alison is researching issues of intercultural

communication in the offshoring of telecommunications. 